Vol. 4, Special Issue 2, January 2017

\title{
Real Time ECG Monitoring System
}

\author{
AbhayPatil ${ }^{1}$, Aniket Kale ${ }^{2}$ \\ Asst. Professor, Department of Electronics and Tele-Communication Engineering, \\ Government College of Engineering Karad, Maharashtra, India ${ }^{1}$ \\ Asst. Professor, Department of Electronics and Tele-Communication Engineering, \\ Dr. DaulatraoAher College of Engineering Karad, Maharashtra, India ${ }^{2}$
}

\begin{abstract}
Current ECG monitoring systems in hospitals use mostly 12 Lead Electrodes along with a DSP signal processing block. The system can be used at doctor's side only \& the patient solely cannot check his/her own ECG. In some cases, the patient cannot get emergency treatment. Also the system is bulky \& complex which makes it inefficient for portable use. We have designed a system with 3 Lead electrodes along with a small signal processing block which uses the technology of Arduino Uno \& MATLAB for signal conversion \& representation. The system is cheap, lightweight, portable. Also it provides the self monitoring facility at patient side.
\end{abstract}

Keywords: ECG, electrodes, patient, doctor, MATLAB.

\section{INTRODUCTION}

Among all vital signs that track an individual's health, II. Half of the adult population was categorized into electrocardiogram (ECG) has a significant importance, pre-hypertension group, another 17\% were found in stagesince it includes meaningful information about the I hypertension with the remaining $3 \%$ in stage-II.

person's heart and performance. It is the primary III. Only 5\% of population reported history of diagnostic for people with cardiac diseases and is a hypertension, which requires urgent attention for standard procedure in current cardiac medicine. Much intervention.

effort has been spent lately to make ECG monitoring an easy and anywhere-anytime available procedure for people with cardiac problems and; especially, for those at risk of heart attack or stroke.

Cardiovascular diseases are some of the most prevalent Forum says,

and serious life-threatening health problems in the world, and represent the main cause of death for people between 44 and 64 years old, and the second most frequent cause of death for people between 24 and 44 years old. Its treatment includes regular check-ups and care which becomes costly for the middle-class people All this facts motivated us to design such a portable system which will bring such patients close to doctor or any concerned person. Information from ECG signal given by our system gives a general idea about patient's heart condition.

\section{LITERATURE SURVEY}

Cardiovascular diseases are the deadliest in the world, killing 9.4 million people every year, according to the World Health Organization (WHO). According to the WHO, cardiovascular diseases which affect the heart and the blood vessels, resulting in heart attacks or strokes in extreme cases, account for $26 \%$ of the deaths in India or 2.5 million[1].

A. Integrated Disease Surveillance Project (IDSP)[2]:

I. Only around a third of the adult population surveyed had normal blood pressure.

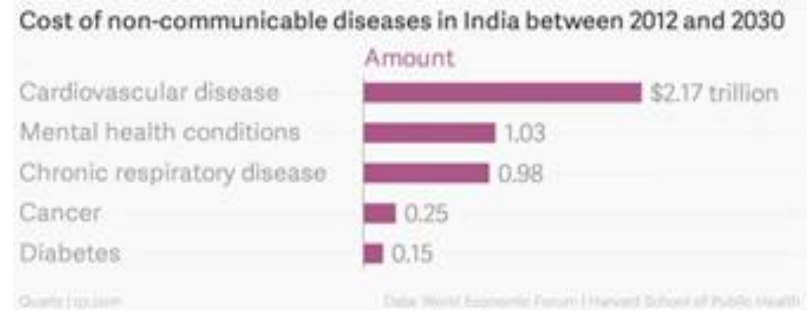

The study estimates the total economic loss due to noncommunicable and mental health diseases in India between 2012 and 2030 to be $\$ 4.58$ trillion - about two and a half times India's GDP — with cardiovascular diseases accounting for almost half of the losses. The losses are calculated by taking into account the money spent on treatment-that ends up hurting personal savings[1]

Heart diseases are the leading cause of deaths among Indians, who account for $60 \%$ of all the heart patients worldwide, a study by Registrar General of India and Indian Council of Medical Research found. Stress, tobacco consumption and obesity are some of the main reasons behind the large number of heart patients in India[1]. 


\section{TROCARDIOGRAM}

An electrocardiogram, also called an EKG or ECG, is a simple, painless test that records the heart's electrical activity. This electrical activity is transformed into waveforms that represent the heart's depolarization repolarization cycle.

\section{A. Function of ECG}

An ECG is a way to measure and diagnose abnormal rhythms of the heart, and helps to diagnose properly. An ECG is used to measure the regularity and rate of heartbeats, also in the position and size of the chambers, the existence of any damage to the heart, and the impact of devices or drugs used to regulate the heart. In a myocardial infarction (MI), the ECG can identify if the heart muscle has been damaged in certain areas, though all the areas of the heart are not covered.

The change in electrical activity is seen under the following situation.

Variation in ionic environment of the heart.

A flaw in the conduction system of the heart.

$\square$ Damage to muscle fibers due to decreased blood supply.

$\square$ Several heart diseases are detected by ECG

TABLE I FONT SIZES FOR PAPERS

\begin{tabular}{|l|l|l|l|}
\hline \multirow{2}{*}{$\begin{array}{l}\text { Font } \\
\text { Size }\end{array}$} & \multicolumn{3}{|c|}{ Appearance (in Time New Roman or } \\
& Regular & Bold & Italic \\
\hline 10 & $\begin{array}{l}\text { table caption (in } \\
\text { Small Caps), } \\
\text { figure caption, } \\
\text { reference item }\end{array}$ & $\begin{array}{l}\text { reference item } \\
\text { (partial) }\end{array}$ \\
\hline 10 & $\begin{array}{l}\text { author address } \\
\text { (in Courier), } \\
\text { cell in a table }\end{array}$ & $\begin{array}{l}\text { abstra } \\
\text { ct } \\
\text { body }\end{array}$ & $\begin{array}{l}\text { abstract heading } \\
\text { (also in Bold) }\end{array}$ \\
\hline 10 & $\begin{array}{l}\text { level-1 heading } \\
\text { (in Small Caps), } \\
\text { paragraph }\end{array}$ & $\begin{array}{l}\text { level-2 heading, } \\
\text { level-3 heading, } \\
\text { author } \\
\text { affiliation }\end{array}$ \\
\hline 10 & author name & & \\
\hline 24 & title & & \\
\hline
\end{tabular}

\section{B. ECG Interpretation}

Heart is muscle that works continuously much like pump. Each beat of heart is set in motion by an electrical signal from within heart muscle. The electrical activity is indicated by an electrocardiogram known as EKG or ECG. Each beat of heart begin with an electrical signal from the sinoatrial node, also known as SA node. The SA node is located in heart right atrium. When heart's right atrium is full with deoxygenated blood the electrical signal spread across the cell of right and left atria. This signal causes the atria to contact or squeeze. This pumps blood through the open valve from the atria into both ventricles. The $\mathrm{P}$ wave on the EKG marks the shrinkage of heart's atria..

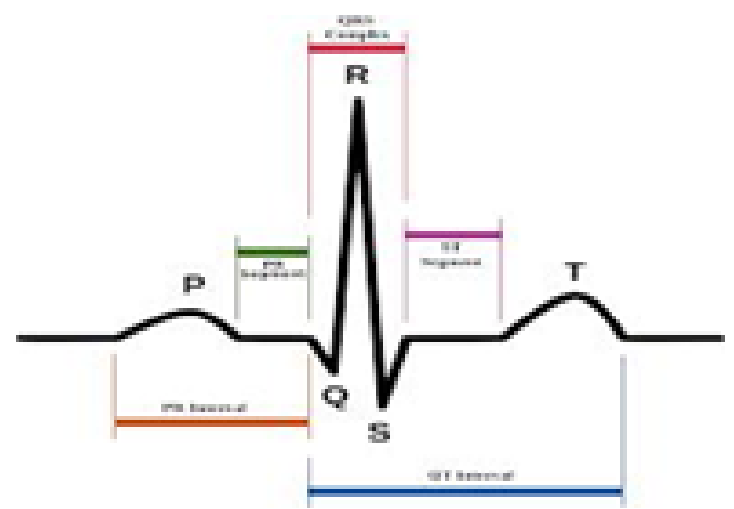

The signal arrives at the atrioventricular node near the ventricle that is AV node. Here it is slowed for instant to allow heart's right and left ventricle to fill with blood. This interval on an EKG is represented by the start of the line segment between the $\mathrm{P}$ and $\mathrm{Q}$ wave. The signal is released and moves next to the bundle of His located in heart's ventricle from the bundle of his the signal fibers divide into left and right bundle branches which run through heart septum. On the EKG, This is represented by $\mathrm{Q}$ wave. The signal leaves the left and right bundle branches through the purkinje fibers that connect directly to the cell in the wall of heart's ventricles. As the signal spreads across the cells of the ventricle wall both ventricle contracts but not at exactly at same moment. The left ventricle of heart contracts an instant before the right ventricle. On EKG the $\mathrm{R}$ wave marks the contraction of heart's left ventricle. The $\mathrm{S}$ wave marks the contraction of heart's right ventricle. The contraction of heart's right ventricle pushes blood through the pulmonary valve to lungs. The contraction of heart's left ventricle pushes blood throughthe aortic valve to the rest of body. As the signal passes the walls of heart's ventricle relax and await for the next signal. On the $\mathrm{EKG}$, the $\mathrm{T}$ wave indicates the point at which heart's ventricle is relaxing. This process continues over and over.

\section{IV.SYSTEM REQUIREMENT AND SPECIFICATION}

\section{A. ECG Electrode}

The heart's electrical activity produces currents that radiate through the surrounding tissue to the skin.

When electrodes are attached to the skin, they sense those electrical currents and transmit them to the electrocardiograph. This electrical activity is transformed into waveforms that represent the heart's depolarization repolarization cycle. Myocardial depolarization occurs when a wave of stimulation passes through the heart and causes the heart muscle to contract. Repolarization is the relaxation phase.

An ECG shows the precise sequence of electrical events occurring in the cardiac cells throughout that process and identifies rhythm disturbances and conduction abnormalities. 
Vol. 4, Special Issue 2, January 2017

B. Amplifier

As the ECG signals are so small there is need to amplify those signals to study the structure of the signal

\section{Filter}

Filter are needed to reduce noise signals occurring in the ECG.

\section{Arduino board}

The signal received through filter is analog in nature To transmit the analog signal to computer it is needed to first convert it into an digital format.To convert analog signal to digital an 10 bit ADC module of the Arduino uno is utilized.

The arduino board has inbuilt memory which stores the sampling pulses and transmit one by one to the computer

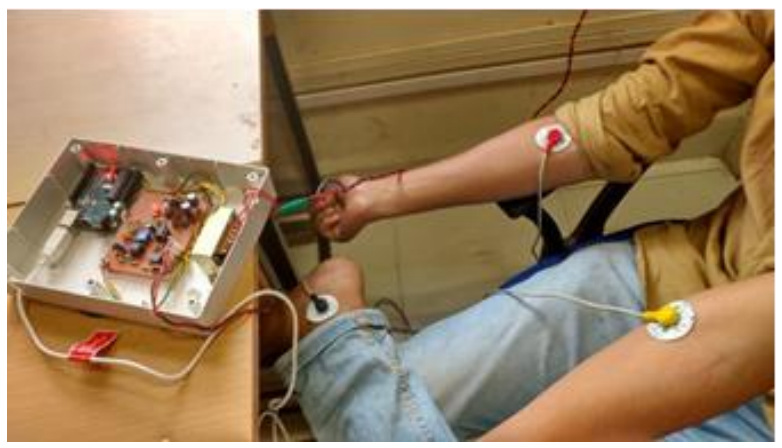

\section{F. MATLAB GUI}

A signal received on the arduino board is stored seen on the matlabGUI.Graphical user interface is prepared using the functions from matlab GUI packages. The real time ECG monitoring is done using GUI functions.

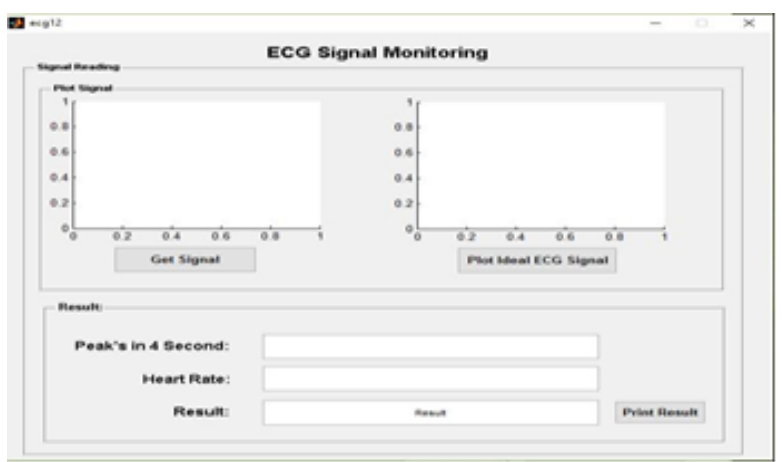

\section{SYSTEM ARCHITECTURE AND IMPLEMENTATION}

In the system architecture shown in above figure, the signals captured by ECG sensors is given to amplifier through 3-lead cable which carries analog signal. This signal is then filtered out using filter IC TL082CP.The filtered signal is then fed to Arduino board where analog signal is converted into digital one to communicate with the computer which uses digital communication principle.
The incoming signal is accessed via MATLAB software where analog ECG signal is plotted for its analysis.

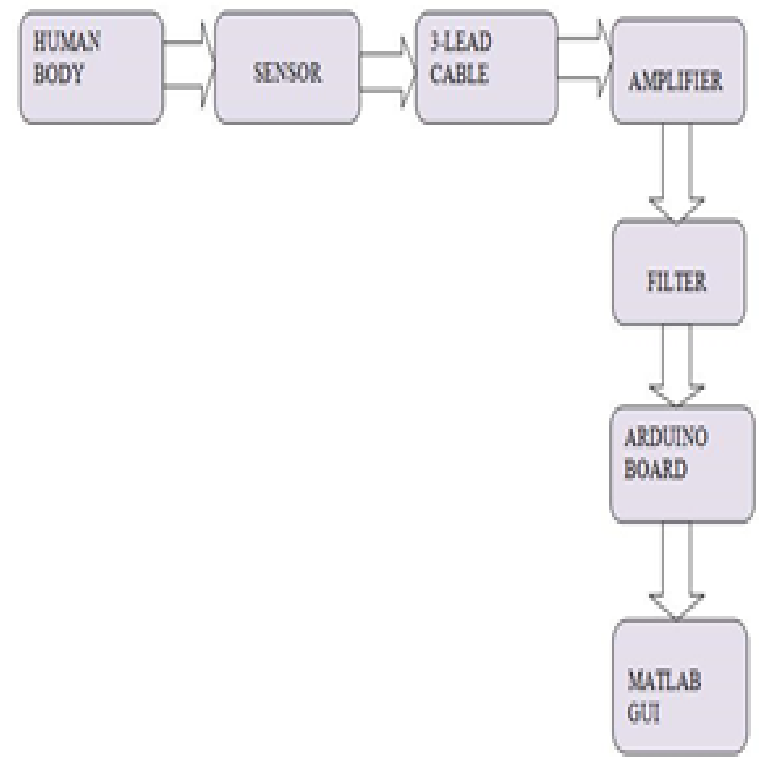

Fig. System Architecture

\section{B. RESULTS}

A. Signal not available

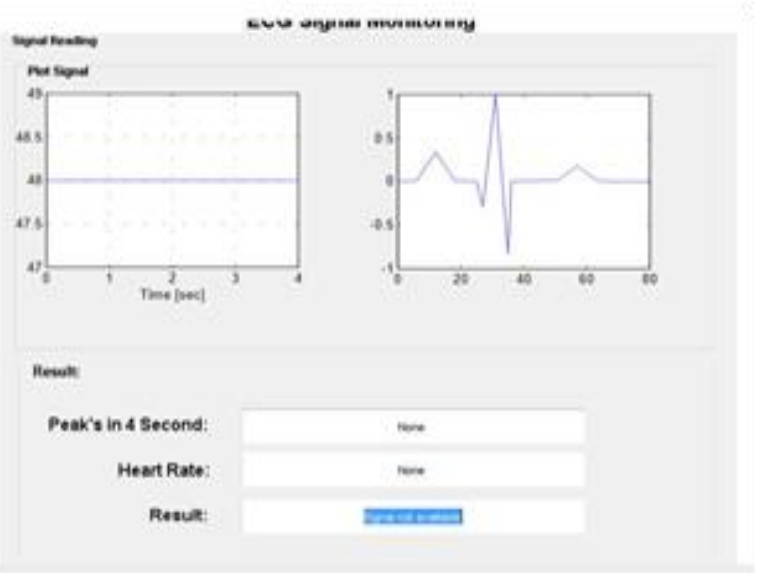

B. Normal ECG waveform

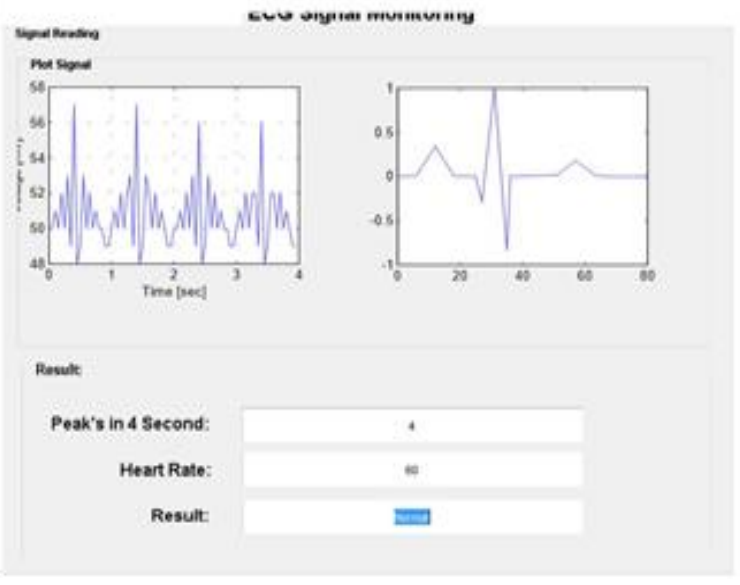




\section{CONCLUSION}

In this paper, we proposed system which will continuously monitor the ECG. This system can monitor and diagnose patient's heart conditions in real time with an ECG sensor and generate alert whenever deviation is found. In future system can be made more accurate by adding more physiological sensors for sensing the ECG.

\section{ACKNOWLEDGEMENT}

We are feeling very proud and honored to submit this project report on "Real-Time ECG Monitoring System" as our project of

Bachelors' level of Engineering. We want to give special thanks to our guide Prof. A. B. Patil Sir for guiding us very well. Also, we wish to give vote of thanks to our Principle Prof.Dr. P. M. Khodke ,HoDProf. M. A. Natu Sir, and all of our teachers for co-operating with us in this project. We wish to give some special thanks to our laboratory staff for their excellent co-operation and friends for their help throughout the course of this project work

\section{REFERENCES}

[1] "The cost of India's heart disease epidemic is over \$2trillion" written by Saptarishi Dutta

[2] "Non-Communicable Disease Risk Factors Survey,2007- 08" citation by National Institute of Medical Statistics, Indian Council of Medical Research (ICMR), 2009,IDSP Non-Communicable Disease Risk Factors Survey, Maharashtra, 2007-08. National Institute of Medical Statistics and Division of Non-Communicable Diseases, Indian Council of Medical Research, New Delhi, India

[3] "Real Time Acquisition and Analysis of ECG signals using MATLAB" International Journal of Advances in Engineering Science and Technology,ISSN: 2319-1120

[4] "Transmission Of Arm Based Real Time Ecg For Monitoring Remotely Located Patient" by Ketaki N. Patil, P. C. Bhaskar, International Journal of Research in Engineering and Technology ,Volume: 03, Issue: 04, Apr-2014

[5] MATLAB (http://mathworks.com). 